\title{
Opening the Black Box-Three Approaches to Interpretation in Participant Observation Studies
}

\author{
Elisabeth Scheibelhofer
}

Department of Sociology, University of Vienna, Austria

Copyright $(2018$ by authors, all rights reserved. Authors agree that this article remains permanently open access under the terms of the Creative Commons Attribution License 4.0 International License

\begin{abstract}
Participant observation (PO) is one of the most important methods in qualitative data collection. Nevertheless, published scholarly work on how to analyze data gained from PO is limited. This article reviews the currently most commonly used forms of analysis involving PO data. It is suggested that we can differentiate three main ways in which PO analysis is done in practice. These three "ideal types" (that in practice are often combined with one another) are, first, anthropological approaches; second, Grounded Theory-oriented studies; and third, analytical work oriented towards social scientific hermeneutics. Each of these three main analytical strategies is embedded in specific research traditions and their epistemological contexts. The article provides an overview of these differing approaches and briefly sketches out their use in current qualitative research involving $\mathrm{PO}$.
\end{abstract}

Keywords Participant Observation, Analyses, Methodological Differences

\section{Introduction}

In their recently published book on participant observation (PO), Breidenstein et al. [1] stated that interpretation in PO still amounts to a black box when looking at textbooks or literature in this research field ${ }^{1}$. Thus, it is timely to ponder on the different practices that are based on varying logics within the social sciences when it comes to interpreting data from qualitative PO.

PO is one of the most well established and relevant techniques of data collection within qualitative social

1 Elizabeth Pierre and Alecia Jackson have referred to the relevance of analysis as such for overall qualitative methods as the 'black hole', citing Patricia Lather[2] and going back to 1991 as a still valid observation (Pierre and Jackson[3]). scientific research ${ }^{2}$. As this method becomes more and more dispersed in various subdisciplines, it is interesting to observe that data collection is far more a focus of the pertinent textbooks than data analysis. On the one hand, such an emphasis might originate from the disciplinary history of anthropology, as discussed below. On the other hand, it might resonate with the understanding that PO requires interpretation over the entire research process. Instead of focusing on ongoing interpretational work, seminal publications rather elaborate on other important topics, such as reflecting the roles taken on by researchers in the field - an important contribution to the methodological development of PO (Adler and Adler[5]; Becker[6]). Still, PO needs interpretation, and especially novice researchers seek texts about how others, after carrying out comparable research, have proceeded in their data analysis.

In this article, I argue that - due to differing social scientific traditions - we can roughly discern three main approaches within the actual work of scholars using PO: first, the anthropological tradition approach; second, introducing Grounded Theory coding into PO research; and third, the methodology of hermeneutic research within the social sciences. These research traditions obviously continue to be in contact with one another, be it through their founders or scholars working within them. Also, in everyday research practice, these approaches are often combined. For matters of clarity in this contribution, these three divergent kinds of PO analyses are separated from one another, as they are based on different approaches to qualitative research per se. They are predicated on diverging epistemologies and research agendas. Moreover, they are also embedded in their respective cultures of how research interests and research questions are framed within a specific scientific community. Discerning these three

2 Yet qualitative interviewing is still used far more frequently in interpretative social scientific research - a fact that has recently met with much criticism (Pfadenhauer and Grenz[4]). 
ideal types of $\mathrm{PO}$ analyses is the core contribution of this article, as such a comparison has so far not been done. This conceptual contribution also entails our understanding that many actual examples of analyzing PO data in research studies are found to combine two of the three presented analytical strategies. Another flaw to such a structuring of thoughts presented here should be mentioned: beyond the three described forms of data interpretation, some empirical work to be identified when doing a literature overview applies qualitative PO but does not necessarily employ any of the strategies discussed here. For example, this is the case when looking at narrative analysis in ethnography (Cortazzi [7]) or semiotic analysis (Vannini 8]). As such forms of data interpretation are (still) comparably in the minority, the following conceptual methodological overview does not concentrate on them.

Still, while being heterogeneous in many respects, the mentioned analytical approaches also have important commonalities that go back to the specificities of doing qualitative research. While considering PO, those who identify themselves as scholars of ethnography, Grounded Theory or hermeneutic research will usually share the understanding that data interpretation begins with the research process itself. It is thus not limited to the analysis of written material or coding. Also, relevant categories and analytical distinctions are developed over the research process. Investigators working with one of the mentioned approaches will also agree that they combine different data sources according to the research needs that may develop in the course of the study itself. Finally, as personal involvement is integral, the role of the researcher within a research endeavor based on PO is specific - and thus much more essential than in other forms of qualitative research.

\section{Comparing Three Differing Analytical Research Practices}

Before going into the further details of this discussion, it should be clear what is meant by PO. Describing the relationship between ethnography and $\mathrm{PO}$, Atkinson and Hammersley [9] made clear that this is not a simple question. Quite convincingly, Kathy Charmaz and Richard Mitchell [10] also defined ethnography as a multifaceted research strategy. PO, by contrast, has been less controversially discussed (compared to ethnography) and is usually described as a method of data collection. One may often find the distinction between PO and non-PO (Atkinson and Hammersley [9]). These definitions used in the literature also point to the fact that the main focus is on data collection and its idiosyncrasies and less on the issue of analysis.

Emerson [11] called what is dubbed here PO as field work. This is an appropriate denomination, as it opens the view on PO as embedded in researchers' actions within a specific field. Yet by now, the notion of a certain "field" that can be localized and delimited is lost (obsolete???) in social scientific research - taking into account the contributions on fluidity, transnationality and what Marcus[12] referred to as the multi-sightedness of research objects, subjects and information. However, by using the term field work, Emerson [11] identified general features that can be attributed to PO in qualitative research as such. Already more than 30 years ago, he stressed the ontological importance of field work for the social sciences:

“(...) even more critical have been efforts to elaborate a distinctive epistemological basis for field research, usually by challenging notions that social actions have "objective" meanings. Instead, field workers have begun to emphasize what has been termed an interpretive paradigm (Overington [13]), which understands 'facts' and 'data' not as objective entities but rather in terms of the social meanings attributed by social actors (including the field researcher) in interactions with others. This tendency in field work leads to a conceptualization of 'subjective', 'situated', or 'constructed' meanings as the object of the research enterprise. Such an intent is incompatible with the assumption that events are objectively meaningful, an assumption that underlies many quantitative approaches and associated standards of validity and reliability" [11].

The primary task being the discovery and description "of meanings or perspectives of actors in the field or specific groups under study", he identified the common roots of field research in the "Verstehen' tradition in European sociology" and in the "American school of symbolic interactionism" [11]. Although these origins are quite historical by now, we still can make out regional differences in PO or in field research deriving from these decisive theoretical contributions to the social sciences. Even though the discourses on methodologies and methods may be described as global - as channeled by international publication organs, such as journals and books, and widely attended international conferences these differences go back to the philosophical foundations of the various research traditions (for an in-depth look into the repercussions of epistemologies on methodologies and methods in qualitative research, see Carter and Little [14]). Nevertheless, we can discern the differing practices of analysis applied to PO data by focusing on research in anthropological traditions, in Grounded Theory, or linked to a hermeneutic understanding of data interpretation.

\subsection{Anthropological Traditions}

Anthropology is the discipline that cannot be separated historically from the development of $\mathrm{PO}$ as both a method and a research strategy. Thus, anthropologists have developed PO over decades and have made the most pertinent contributions to the method. Being closely, personally and regularly associated, sociology and other disciplines took up discussions on the importance (...) - 
an issue tracing back to Malinowski's classic texts 15$]^{3}$. Yet being "in the field" frequently and for lengthy periods of time remains one of the most prominent features of how PO is used in ethnography. Field research is therefore another expression often used here to stress immersion into a specific social environment. The diverse turns within the discipline led to a number of important contributions for the method in the social sciences as such. These topics include the rethinking of the "field", its constitution, and the positioning of the researcher within it (Al-Hardan [18]). The problems of access, going native, and how to write field notes are commonly discussed questions in the literature. Typically, the question of how data are collected is thus much more in focus when going through the seminal textbooks and publications than how data are interpreted. Of course, the overall process of doing fieldwork is an interpretive endeavor - a fact that is regularly pointed out by scholars. Yet focusing on the question of PO data analysis, the accounts given in ethnographic research are few. Arthur Vidich [19] was one of the prominent scholars to defend such a position that serves to concentrate on the findings themselves instead of focusing on rigid methodological frameworks. Amir Marvasti [20] has argued in a similar fashion. Thus, many accounts of actual methodological approaches applied in field research concentrate on data collection aspects, while rather scarce information is given regarding actual data interpretation.

Still, some work can be identified when searching more closely for PO data analysis in anthropological research. This applies especially to scholars working on a phenomenological foundation. They base their reasoning mostly on the theoretical contributions of phenomenology (Husserl [21]), as exemplified by Warren [22] who "characterizes her field work findings as phenomenological in that they present 'meanings of the gay world as the members experienced it" (cited in Emerson [11]). Applying the technique of eidetic reduction to study the essences of phenomena, the studies authored by Michaela Pfadenhauer [4, 23] and her colleagues are a recent example of ethnographic research and phenomenologically based analyses.

Beyond such phenomenological approaches, a typical representative of the anthropological tradition can be found in "Participant observation. A guide for field workers" by Kathleen M. DeWalt and Billie R. DeWalt[24]. The authors start out from the assumption that the main task of analyzing data is to summarize "large quantities of data into understandable information from

3 However, discussions taking place after the publication of Malinowski's diaries (Malinowski[16]) led to a differentiated view of his actual field work and how he conceived himself as an observer. It was James Clifford [17] who pointed out that there is a difference between the observer who gathers data and reflects upon this process (more or less in private) and the actual written story he or she produces. which well-supported and well-argued conclusions are drawn". According to DeWalt and DeWalt, this goal is reached through extensive phases of reading and re-reading the material produced by the actors themselves, as well as by reading the field notes and memos produced while (and after) doing field work. Ethnographic writing and the writing of field notes are thus specifically important to the anthropological research tradition - a fact that is reflected in the ongoing debates on the topic (e.g., Atkinson et al. [25]; Emerson, Fretz, and Shaw [26]; Wolfinger [27]). What is agreed about in these debates is that the writing process itself is an interpretive and iterative process in which writing, reading and thinking are the principal techniques applied. The analytical process may also be characterized as writing in that sense (for a recent critical contribution on the writing culture in ethnography, see Atkinson [28]). Yet the stages of reading/thinking/writing throughout the research process differ from one another, as the researcher has different questions in mind each time (DeWalt and DeWalt [24]). The authors themselves acknowledge the difficulties of describing the method of data analysis when stating that "Despite several recent, quite good discussions of coding qualitative data (...), of all of the somewhat mystical activities associated with the method of participant observation, analysis of data is the most mysterious" [24].

However, such methodological opaqueness is not perceived as a flaw that would need to be overcome with further work in describing the process of data interpretation in anthropological PO. Quite on the contrary, this vagueness is considered a necessity, as only part of the analysis is described by the authors as logic. This latter part includes the building of categories by reviewing and reorganizing the material [24]. Yet the rest of the analysis unfolds when "some of the connections between observations and the insights that form part of the process of analysis take place subconsciously" [24].

The form of logical operation that is alluded to here comes close to the first steps of what Charles S. Peirce [29] described as abduction, introducing this mode of operation to philosophical discourse. Today, abductive inference has attracted considerable interest in both qualitative methodology and ethnographic reasoning. While one might critically discuss its standing as logic reasoning, such as deduction and induction ${ }^{4}$, proponents within the debate have argued that neither through induction nor deduction may we arrive at new solutions for problems that have not been solved up to date. This is because in the case of these classic forms of inference, results are only reformations of formerly existing elements (Reichertz [31]). Thus, no new knowledge can be produced on this logical basis. Peirce [29] assumed that new knowledge needs to be established if we come across puzzles that we

4 Brent [30], for example, called the process of abduction guessing. 
cannot solve with our existing repertoire. The same happens within anthropological (and other qualitative) research when we discover new social forms or combinations of actions. If a problem - such as making sense of field data - cannot be solved with existing knowledge, we need to be focused on a problem and at the same time let our mind dwell on it freely so that new associations come to our mind. Yet this new form of knowledge is a preliminary one, as it still needs to be validated through further analytical probing of empirical material in the case of social scientific qualitative research. Agar [32] has even argued that the question of boundaries of ethnographic work can only be answered by (also) looking at the research logics applied.

Apart from abductive procedures, data analysis in ethnography means that researchers repeatedly prospect for social patterns or orders within the collected material and the protocols of $\mathrm{PO}$ and other kinds of data gathered. In order to do so, they move back and forth in the material. One major technique in doing so is to break down the data into manageable sections of "basic descriptive units" (Maggs-Rapport [33]). Ethnographic researchers usually also try to reduce the material so that data which "might confuse the analysis process" is "sifted out" in an early stage [33].

In summary, compared to the other two methodologies of data interpretation in PO discussed later on in detail, ethnographic interpretation techniques stand out due to their principal analytical procedure - the undertaking of reading and re-reading of field notes and other material. Based on available descriptions in the literature, students or inexperienced researchers may have a hard time working out what is actually done with the data ${ }^{5}$. Repeated reading is described as an immersion into the protocols of PO. Such a technique makes it necessary to accumulate many protocols in the first place in order to immerse oneself in continuous reading. In these accounts, researchers find themselves at a crucial stage of analysis and prefer working alone than within a team. Immersing oneself into texts may contribute to abductive conclusions. However, these conclusions in terms of abduction need further probing, as described by Peirce [29]. In ethnographic studies as well, these initial insights gained through immersion are perceived as provisional and require further interpretive investigation.

\subsection{Grounded Theory}

When Barney Glaser and Anselm Strauss developed

5 Here, one should add that qualitative data analysis per se needs to be learned by way of a hands-on approach. As Lueger [34] pointed out, this kind of work is similar to a handicraft or fabricating artisanry: Its actual implementation is difficult to explain, so that the techniques rely heavily on doing analysis, as novices, in course-like situations or in actual research projects.
Grounded Theory, they emphasized the inductive moment of their research. To these authors, going into the data meant that one could count on "coming back" with valid mid-range theories of the social world at interest (Kelle [35]; Reichertz [31]; Strübing [36]). During the subsequent decades, Glaser and Strauss proceeded in different methodological directions when they further developed their respective views of Grounded Theory - as did other researchers identified with that theory ${ }^{6}$. By now, there are divergent traditions with different epistemological positions followed by social scientists.

When Grounded Theory was first developed, the work of Glaser and Strauss [38] did not specify very closely how (and which) data is best to be collected for Grounded Theory research. Nevertheless, from the outset of Grounded Theory, PO had an outstanding status compared to other data sources. This preference for PO was disclosed in their book on dying as a status passage. In their perspective, PO consists of "field observations and interviews":

(...) participant observation is an especially reliable method of data collection when one is interested in sequential interactions within natural situations*. It is also the most 'adequate' and 'efficient' method of obtaining information on many "properties of the same object"”**7.

Together with Juliet Corbin, Anselm Strauss highlighted that Grounded Theory is a research methodology - and not merely a way to code one's data. At the same time, they had a vivid interest in giving first-hand insights into their actual analytical work, so that novices and more advanced researchers could take up Grounded Theory without attending specialized training or classes. However, this endeavor has also resulted in publications that turned the creative process of coding into a procedure seemingly easy to follow (e.g., Strauss and Corbin [41]). This was certainly not their intention, as Strauss and Corbin, in this very book, variously emphasized the creative process that cannot be broken down into procedural rules. The influence of their work on researchers seeking a simple way to carry out qualitative research without having completed adequate training has certainly been significant over the last years. This development has resulted in a certain strand of work that claims to adhere to Grounded Theory while operating on a rather superficial level compared to the methodological

6 Their professional journey did not only go into different directions, following the usual account given in the Grounded Theory literature (Strübing [37]), it also started off from different philosophical and epistemic cultures. While Glaser was highly influenced by his studies at Columbia University, Strauss, after studying with Merton and Lazarsfeld and thriving in a positivist intellectual environment, studied in Chicago and was highly influenced by Blumer.

7 Asterisks in this citation mark the work that was referred to in the original text: First, the article by Howard S. Becker and Blanche Geer [39] on comparing PO and interviewing is mentioned here, as Glaser and Strauss refer to their definition of "natural situations". The second citation points to the work by Morris Zelditch [40] on field studies. 
reasoning of its founders and offering more content analysis and descriptions than carrying out substantial interpretive work. Moreover - and unrelated to Strauss' and Corbin's work - the appearance of computer-assisted programs based on ideas of Grounded Theory coding might have had an effect on spurring analytical research into the direction of "quick and dirty" coding, as Kathy Charmaz has repeatedly referred to this kind of superficial qualitative research.

Nevertheless, the mentioned authors' later studies had, as a common notion, their focus on theory building from an early stage of the research process. While new developments have become very important within Grounded Theory over the past decades, this stress on theory building as its main goal is still present. Since the 2000 s, sophisticated ways of precise analyses, such as situational analysis, have been proposed by Adele Clarke [42], while Charmaz's [43, 44] work on constructivist Grounded Theory is gaining international importance. In a text focusing on ethnographic work and Grounded Theory, Kathy Charmaz and Richard Mitchell [10] also gave insights into the analysis of PO data in Grounded Theory. In line with these new developments in Grounded Theory, they made clear that their approach is based on the theoretical perspective of constructivism, assuming that multiple realities are constructed through a mutual creation of knowledge by researchers and research participants [10]. In a nutshell, the process of analysis encompasses coding, comparative work, writing memos and theoretical sampling. The last component is based on prior analytical results and thus, from early on in a study, Grounded Theory researchers begin with coding, memo writing and formulating hypotheses about possible links between these codes. In a constructivist take, researchers are no longer outsiders looking at data. Rather, they enter into communication with data and interpret it interactively and meaningfully (for a broader view on constructionist theories and their implications for qualitative research, see also Holstein and Gubrium [45]). Thus, researchers' positionings need to be questioned continuously while accompanying the research and the analytical process. Coding then means to engage in a social process in the course of which initially, during open coding, only very small parts of text (some words or a line at a maximum) are regarded. To analyze $\mathrm{PO}$, and in contrast to this approach, Charmaz and Mitchell suggested protocols as a totality because:

"Any set of data already has some level of interpretation written into its collection. Line-by-line coding stays close to the data. If data consists of mundane observed behavior, with little contextual framing, line-by-line coding may not be helpful. (...) Coding whole anecdotes, scenarios, and sketches may work better for ethnographic observations than line-by-line coding [10]."

This suggestion may prove especially helpful if researchers work alone in a given project. If PO protocols may be interpreted within a research group, line-by-line coding may still lead to important theoretical insights, as the observers' interpretations can be reflected more closely when compared to coding by incident. Yet the discussion within Grounded Theory is still ongoing in this respect.

Coding, and even preceding procedures, are typically accompanied by memo writing. This is the main stage upon which theory building is pushed forward - and in the case of analyzing data collected, memo writing is an important aspect of the interpretive process. Writing memos can involve developing codes and categories. These descriptions of codes become more and more comparative as the research project evolves. Their meaning for the social setting under study is explored, whilst memos might also include excerpts from the scholarly literature found to be relevant to link the ongoing research process to published studies ${ }^{8}$.

Open coding is especially important at the beginning of the research process. It is an inherently creative process that is meant to link the social phenomena in a new way to the empirical data in comparison to everyday understanding. With more data and preliminary concepts to be established, comparative work begins in the analysis. This comparative phase was especially detailed in the research done by Strauss and Corbin, whereas Charmaz does not use it, instead introducing focused coding as a separate work step. This analytical phase brings to the fore the codes in interpretive work that are deemed more important, as regards research interests, than other codes (e.g., Charmaz and Smith [47]). Strauss and Corbin have described the last step in coding as selective and as one that is meant to close gaps in developing Grounded Theory.

Summing up, it can be concluded that while PO was important for Grounded Theory work from the beginning, the ways to analyze its data have varied across different research streams within that perspective. While Glaser and Strauss did not provide much detail of their analytical work initially, Anselm Strauss and Juliet Corbin attempted to render Grounded Theory analyses more readily accessible through their publications on the actual intellectual work involved, such as coding, memo writing and comparing. This comparative aspect is probably the one that stands out when contrasting the everyday analytical work of the three research traditions described here, also in terms of PO analysis: At a very early stage, Grounded Theory analysis draws comparisons between PO data 'snippets' across the cases observed. Charmaz' and other constructivist approaches have brought

8 Although Grounded Theory scholars seriously disagree when it comes to the significance of scholarly literature, there is a common understanding as far as I can see that existing literature should certainly not overrule the insights we gain from coding our data [46]. 
researchers' positionality into the picture of analyzing data (including PO): Only if researchers' own perspectives are reflected upon may one attain an adequate understanding of the social worlds under study (Charmaz [48]). From the point of view of PO, it is especially problematic that a large part of the literature on Grounded Theory factors out data collection. As in PO, the analytical process of Grounded Theory starts with the collection of data, and this gap needs to be more closely addressed when further developing this method.

\subsection{Hermeneutic Social Sciences}

Hermeneutics in the social sciences aims to reconstruct the societal meaning of any form of interaction - spoken or non-spoken - and any kind of social outcomes these interactions may spur. Actions are the core of this methodology, as actors within a specific situation need to interpret their own doing and the doing of others, referring their activities to one another in a particular way so that interaction is successful. Thus, PO is core to hermeneutics in the social sciences. It is based on interpretational work in an attempt to explicate meanings that participants may find difficult to articulate or are not even aware of, as is the case with tacit knowledge shared by a certain group of people (Ajjawi and Higgs [49]). Yet such tacit knowledge serves to structures everyday life and the social order within life worlds. Hermeneutic research concentrates on questions as to how individuals appropriate routines and interpretations of present social situations that are historically embedded in situations, institutions and structures (Reichertz [50]). In their appropriation, individuals either conform with (and thus confirm) existing rules and social structures or they change practices and social meanings through their actions.

The hermeneutic circle is core to hermeneutic epistemology. There is a variety of approaches within hermeneutic philosophies and hence methodologies building upon them (Bontekoe [51]). The hermeneutic circle is a metaphor for a mode of interpretation that moves constantly between small parts (of data) and the overall interest (in the case of the social sciences, this encompasses the evolving understanding of the social to be studied). Within this movement, each new insight may give a new meaning to the prior insight, such that understanding becomes a process that is "circular and iterative" (Ajjawi and Higgs [49]). As a consequence, the research process is an open one - taking up new questions and insights, thus leading the analysis into unforeseen directions. Doing this kind of interpretational work is based on the competences that we also use in our everyday lives, such as listening, asking, observing and trying to "make sense" of the information we can process. Using these "first-order constructs" (Schütz[52]) for a start, we are in a different situation while doing research than we are in everyday life, as we have time to reflect upon our interpretations when analyzing data translated into texts. This is why hermeneutic research typically concentrates on texts or data that have been transformed to texts in a prior step of selection and interpretation.

The main quality criterion in interpretational work is whether other adult members of the same society may be able to follow its reasoning. If this reconstruction can be shared intersubjectively ("intersubjektive Nachvollziehbarkeit"), the result of hermeneutic analysis is validated. As the goal of analytical work is the reconstruction of latent meanings that permit insights into social structures relevant to people's everyday lives, preference in hermeneutic research is usually given to "natural" data which is produced by the field and the social actors to be studied without being influenced by the researchers. If such data are not available, hermeneutic scholars will opt for methods that produce data that are less constructed by the researchers involved but rather structured by the relevance of actors in the respective field. Here, PO comes into play and has its firm standing in hermeneutic approaches when the focus of research interest is on practices and interaction.

Even more so than in anthropological and Grounded Theory research, hermeneutic research is divided regionally into different scientific communities that base their research on differing philosophical and methodological reflections. Overmann's "objective hermeneutics" has been important to German-speaking scholars (Oevermann, Allert, and Konau [53]). Since then, the debate around his work has additionally led to significant theoretical, methodological and methodical innovations, followed, e.g., by the establishment of the "hermeneutic sociology of knowledge" (Reichertz [50]) and the most recent introduction of communicative constructivism among a group of German-speaking researchers (Soeffner [54]). In these approaches, "knowledge" is understood as the result of a specific societal construction process that needs to be reiterated by research (Berger and Luckmann [55]; Reichertz[56]). In these branches, PO remains an important analytical pathway, as knowledge and communication are perceived to be embedded in social interactions.

Philosophical and methodological reflections are valued highly within hermeneutic research in the social sciences. Yet scholars also reflect upon their actual research practices, including the analysis of PO data. Two examples are used here in order to give insights into the interpretive approach. Rola Ajjawi and Joy Higgs (Ajjawi and Higgs [49]) described six stages in PO analysis: The first step of "immersion" encompasses the transcription of data in taped conversations and interviews into texts. In the case of PO, protocols are composed. Re-reading of these transcripts and protocols leads to a preliminary interpretation (for the description of these analytical steps, cf. ibid. pp. 621f.). During the second step - termed "understanding" - participants' first-order and other 
constructs are identified. The third step of "abstraction" aims at reconstructing the second-order understandings of the researchers involved in the process of interpretation. Fourth, a synthesis of significant themes is developed. These themes are consecutively studied across the material in order to deepen their understanding. In a fifth step, the scientific literature is reviewed according to the themes reconstructed in the preceding analysis. The last step is designed to absorb other researchers' critique and feedback on the results and to report the final interpretations of the research findings to a broader scholarly public.

While Ajjawi and Higgs described their analysis of PO and other data they included in their research on communicative strategies of physiotherapy practitioners, Manfred Lueger's book on qualitative methods explicitly highlighted the analytical process from a social scientific hermeneutical point of view (Lueger [34]). Ajjawi's and Higgs' first step of “immersion" corresponds to Lueger's "descriptive analysis" [49]. According to Lueger, and based on the PO protocols, the main analytical work starts out with a "perspectivist analysis of the structures of meaning". In this phase, various possible interpretations in terms of meaning are applied to the material at hand in order to open up as many venues as possible for its understanding ${ }^{9}$. The following analytical procedure encompasses "detailed analyses" of different levels (as applicable to the data, e.g., of the processes involved, actions, situations, social groups and the context of the observed). Finally, the results of the three analytical steps are integrated and tested before writing the scientific report.

Although the two descriptions show similarities in their analytical procedures, significant differences are also to be pointed out. While Ajjawi and Higgs essentially rely on a strategy similar to the immersion procedure found in anthropological analysis, Lueger interprets short texts by examining the horizon of possible social meanings. Here, the principle of sequentiality (Soeffner and Hitzler [57]) has its significance as it does in hermeneutics. By following the time line of events within the analysis, potential interpretations can be excluded step by step. Thus, the logic of the single case is at the core of interest in hermeneutical research. Comparisons with other cases only follow at a later stage. This focus on one case at a time within the research process is one of the main elements that stands out when contrasting the three ways to interpret $\mathrm{PO}$ data.

9 Here, the aforementioned "intersubjektive Nachvollziehbarkeit" sets the limit: The text interpretations that are socially comprehensible to other interpretations are the only ones to be retained in the analysis. However, all possible interpretations need to be exhausted.

\section{Conclusions}

Why do researchers decide on adopting one or another method of interpreting qualitative data from PO? As Carter and Little (Carter and Little [14]) emphasized for qualitative methods and methodologies in general, scholars are highly influenced in their axiological epistemic choices. From their training and reading, they have learned to frame research interests and research questions in specific ways, such that certain methodologies are those of choice to them and not to others. These methodological traditions then influence the selection of methods, both for data gathering and for data analysis.

While PO requires considerable training and reflection in diverse aspects, it is certainly also useful to enter into a scholarly debate about the methodologies underlying the choice of PO - and the choices of data interpretation carried out within qualitative research. This article demonstrated that the presented ideal typical forms of data interpretation vary significantly from one another due to their epistemic and methodological foundations. Besides research interests, group-specific factors also come into play when choosing a single methodology, method and, as part of the latter, one way of data interpretation: According to the relevant scientific community, scholars will choose those methodologies and (analytical) methods with which they are familiar and which are deemed appropriate in their discipline or other addressed groups of peers.

Reflecting upon the different kinds of analyses for PO data leads to further explorations needed in terms of establishing quality criteria applicable to interpretive methods. Do we in fact need different criteria according to the epistemic and methodological traditions, even with qualitative methods? Some researchers, such as Amir Marvasti (Marvasti [20]), have argued that no canon of analytical methods for PO data is at all necessary. Instead, Marvasti suggested that "research findings (the product of analysis) should flow from the empirical observations and make sense. If the reader cannot understand how the researcher began with a particular set of observations and arrived at the findings, then the analysis has failed", and continues that " $(. .$.$) the quality of the analysis should not$ be judged solely on the researcher's unrelenting adhering to this or that particular technique which happens to be in vogue at the time" (ibid., 363). While probably no qualitative researcher would find it troublesome to agree with the first part of the cited statement, the second part would perhaps create more momentum in a discussion over quality criteria in qualitative research.

Having laid out the specifics of the analytical approaches under study, it becomes quite clear that interpreting PO data is closely linked to the main methodological principles within the diverse fields of research methodologies and methods described above. 
The three main different approaches to analyze PO data also influence one another and thus have many aspects in common. One of these shared aspects is the process of abduction as one step to generate new insights into phenomena that cannot be understood with the current body of research. This epistemological basis is reflected more or less in the three branches discussed above, yet it is present in all of them.

By now, one might add that PO has become the most important method of data collection applied to study societies - together with research that is mainly based on qualitative interviews. Having reached this significance, it is timely to reflect in more detail upon all aspects of the research process, including analysis. This contribution made an effort to bring the question of data analysis to the fore front of the ongoing debate on the development of interpretive methods in the social sciences.

\section{Acknowledgements}

This research was sponsored by the Norface program via FWF collaboration (FWF Project Number I 2025-G16, 2015-2018; national project leader: Elisabeth Scheibelhofer.)

\section{REFERENCES}

[1] G. Breidenstein, H. Stefan, H. Kalthoff, B. Nieswand. Ethnografie: Die Praxis der Feldforschung, UVK-Verl.-Ges., Tübingen, 2013.

[2] P. A. Lather. Getting smart: Feminist research and pedagogy with/in the postmodern, Psychology Press, 1991.

[3] E. A. S. Pierre, A. Y. Jackson. Qualitative data analysis after coding, Qualitative Inquiry, Vol.20, No.6, 715-719, 2014.

[4] M. Pfadenhauer, T. Grenz. Uncovering the Essence. The Why and How of Supplementing Observation with Participation in Phenomenology-Based Ethnography, Journal of Contemporary Ethnography, Vol.44, No.5, 598-616, 2015.

[5] P. A. Adler, P. Adler. Observational techniques, In N. K. Denzin, Y. S. Lincoln (Eds.), Handbook of qualitative research, Sage, Thousand Oaks, CA, 377-392, 1994.

[6] H. S. Becker. Problems of inference and proof in participant observation, American sociological review, Vol.23, No.6, 652-660, 1958.

[7] M. Cortazzi. Narrative Analysis in Ethnography, In P. Atkinson, A. Coffey, S. Delamont, S., J. Lofland, L. Lofland (Eds.), Handbook of ethnography, Sage, Thousand Oaks, CA, 384-394, 2001.

[8] P. Vannini. Social Semiotics and Fieldwork Method and Analytics, Qualitative Inquiry, Vol.13, No.1, 113-140, 2007.
[9] P. Atkinson, M. Hammersley. Ethnography and Participant Observation, In N. K. Denzin, Y. S. Lincoln (Eds.), Handbook of qualitative research, Sage, Thousand Oaks, CA, 248-261, 1994.

[10] K. Charmaz, R. G. Mitchell. Grounded Theory, In P. Atkinson, A. Coffey, S. Delamont, S., J. Lofland, L. Lofland (Eds.), Handbook of ethnography, Sage, Thousand Oaks, CA, 160-174, 2001.

[11] R. Emerson. Observational field work, Annual Review of Sociology, Vol.7, No.1, 351-378, 1981.

[12] G. Marcus. Ethnography in/of the world system: The emergence of multi-sited ethnography, Annual review of anthropology, Vol.24, No.1, 95-117, 1995.

[13] M. Overington. Doing the What Comes Rationally: Some Developments in Metatheory, The American Sociologist, 2-12, 1979.

[14] M. S. Carter, M. Little. Justifying knowledge, justifying method, taking action: Epistemologies, methodologies, and methods in qualitative research, Qualitative health research, Vol.17, No.10, 1316-1328, 2007.

[15] B. Malinowski. Argonauts of the Western Pacific: An account of native enterprise and adventure in the archipelagoes of Melanesian New Guinea, Routledge, London, 2002.

[16] B. Malinowski. A Diary in the Strict Sense of the Word, Harcourt, Brace, and World, New York. 1967.

[17] J. Clifford. The predicament of culture, Harvard University Press, Cambridge, 1988.

[18] A, Al-Hardan. Decolonizing Research on Palestinians towards Critical Epistemologies and Research Practices, Qualitative Inquiry, Vol.20, No.1, 61-71, 2014.

[19] A. J. Vidich. Participant observation and the collection and interpretation of data, American Journal of Sociology, Vol.60, No.4, 354-360, 1955.

[20] A. B. Marvasti. Analysing Observations, In U. Flick (Ed.), the SAGE Handbook of Qualitative Data Analysis, SAGE Publications Ltd., London, 354-376, 2013.

[21] E. Husserl, Phänomenologie und Anthropologie, Philosophy and phenomenological research, Vol.2, No.1, 1-14, 1941.

[22] C. A. B. Warren, Identity and Community in the Gay World. Wiley, New York, 10, 1974.

[23] M. Pfadenhauer, Doing Phenomenology: Aufgrund welcher Merkmale bezeichnen wir ein Handeln als »kompetentes Organisieren« ?, Phänomenologie und Soziologie, VS Verlag für Sozialwissenschaften, Wien, 339-348, 2008.

[24] K. M. DeWalt, B. R. DeWalt. Participant observation: A guide for fieldworkers, Altamira Press, Plymouth, 179, 2010 .

[25] P. Atkinson, A. Coffey, S. Delamont, J. Lofland, L. Lofland (Eds.). Handbook of ethnography, Sage, Thousand Oaks, CA, 2001.

[26] R. M. Emerson, R. I. Fretz, L. L. Shaw. Writing Ethnographic Fieldnotes, University of Chicago Press, Chicago, 2011. 
[27] N. H. Wolfinger. On writing fieldnotes: collection strategies and background expectancies, Qualitative research, Vol.2, No.1, 85-93, 2002.

[28] P. Atkinson. Ethnographic Writing, the Avant-Garde and a Failure of Nerve. International Review of Qualitative Research, Vol.6, No.1, 19-35, 2013.

[29] C.S. Peirce. Collected papers of Charles Sanders Peirce, Harvard University Press, Cambridge, $121 \mathrm{ff}, 1935$.

[30] J. Brent. Charles Sanders Peirce: A Life, Indiana University Press, Bloomington, 1998.

[31] J. Reichertz. Abduktion: Die Logik der Entdeckung der Grounded Theory, In G. Mey, K. Mruck (Eds.), Grounded theory reader, Vol2. VS Verlag für Sozialwissenschaften, Wiesbaden, 279-297, 2011.

[32] M. Agar. An Ethnography by any other name, Paper presented at the Forum Qualitative Sozialforschung, Forum Qualitative Social Research, 2006.

[33] F. Maggs-Rapport, Combining methodological approaches in research: ethnography and interpretive phenomenology, Journal of Advanced Nursing, Vol.31, No.1, 219-225, 2000.

[34] M. Lueger. Interpretative Sozialforschung: Die Methoden, Facultas, Wien, 2010.

[35] U. Kelle. "Emergence" vs." Forcing" of Empirical Data? A Crucial Problem of" Grounded Theory" Reconsidered, Historical Social Research/Historische Sozialforschung, Supplement, 133-156, 2007a.

[36] J. Strübing. Was ist Grounded Theory?, In Grounded Theory, VS Verlag für Sozialwissenschaften, Wiesbaden, 2014.

[37] J. Strübing, Just do it? Zum Konzept der Herstellung und Sicherung von Qualität in grounded theory-basierten Forschungsarbeiten, Kölner Zeitschrift für Soziologie und Sozialpsychologie, Vol.54, 318-342, 2002.

[38] B. G. Glaser, A. L. Strauss. Temporal aspects of dying as a non-scheduled status passage, American Journal of Sociology, Vol.71, No.1, 48-59, 1965.

[39] H. S. Becker, B. Geer. Participant observation and interviewing: A comparison, Human Organization, Vol.16, No.3, 28-32, 1957.

[40] M. Zelditch Jr.. Some methodological problems of field studies, American Journal of Sociology, Vol.67, No.5, 566-576, 1962.

[41] A. L. Strauss, J. Corbin. Basics of qualitative research: techniques and procedures for developing grounded theory, Sage, Thousand Oaks, CA, 1998.

[42] A. E. Clarke. Situational analysis: Grounded theory after the postmodern turn, Sage, Thousand Oaks, CA, 2005.

[43] A. Bryant, K. Charmaz. The Sage handbook of grounded theory, Sage, Thousand Oaks, CA, 2007.
[44] K. Charmaz. Constructing grounded theory: A practical guide through qualitative analysis, Sage, Thousand Oaks, CA, 2006.

[45] J. A. Holstein, J. F. Gubrium. The constructionist analytics of interpretive practice, In N. K. Denzin, Y. S. Lincoln (Eds.), The Sage handbook of qualitative research, Sage, Thousand Oaks, CA, 341-358, 2011.

[46] U. Kelle. Theoretisches Vorwissen und Kategorienbildung in der „Grounded Theory“, In U. Kuckartz, H. Grunenberg, T. Dresing (Eds.), Qualitative Datenanalyse: computergestützt, VS Verlag für Sozialwissenschaften, Wiesbaden, 32-49, 2007b.

[47] K. Charmaz, Grounded Theory, In J. A. Smith (Ed.), Qualitative psychology: A practical guide to research methods, Sage, Thousand Oaks, CA, 53-84, 2003.

[48] K. Charmaz, Teaching Theory Construction With Initial Grounded Theory Tools A Reflection on Lessons and Learning, Qualitative health research, Vol.25, No.12, 1610-1622, 2015.

[49] R. Ajjawi, J. Higgs. Using Hermeneutic Phenomenology to Investigate How Experienced Practitioners Learn to Communicate Clinical Reasoning, Qualitative Report, Vol.12, No.4, 612-638, 2007.

[50] J. Reichertz. Hermeneutische Wissenssoziologie. In R. Buber, H. Holzmüller (Eds.), Qualitative Marktforschung, Gabler, Wiesbaden, 111-125, 2009.

[51] R. Bontekoe. Dimensions of the hermeneutic circle. Atlantic Highlands, NJ: Humanities Press International, 1996.

[52] A. Schütz. Gesammelte Aufsätze I: Das Problem der sozialen Wirklichkeit, Nijhoff, Den Haag, 1971.

[53] U. Oevermann, T. Allert, E. Konau. Zur Logik und Interpretation von Interviewtexten. Fallanalyse anhand eines Interviews mit einer Fernstudentin, In T. Heinze, et al. (Eds.), Interpretation einer Bildungsgeschichte, päd.extra, Bensheim, 15-39, 1980

[54] H. G. Soeffner, Kommunikativer Konstruktivismus: Theoretische und empirische Arbeiten zu einem neuen wissenssoziologischen Ansatz, Springer-Verlag, 2013.

[55] P. Berger, T. Luckmann. Die gesellschaftliche Konstruktion der Wirklichkeit. Eine Theorie der Wissenssoziologie. Fischer, Frankfurt am Main, 1972.

[56] J. Reichertz. Hermeneutik der Kulturen - Kulturen der Hermeneutik: zum 65. Geburtstag von Hans-Georg Soeffner, UVK-Verlagsgesellschaft, Konstanz, 2004.

[57] H. G. Soeffner, R. Hitzler. Hermeneutik als Haltung und Handlung: über methodisch kontrolliertes Verstehen. In N. Schröer (Ed.), Interpretative Sozialforschung: auf dem Wege zu einer hermeneutischen Wissenssoziologie, Westdeutscher Verlag, Opladen, 28-54, 1994. 